\title{
Article \\ Electrochemical Behaviour of Tocopherols: Possibilities of Their Simultaneous Voltammetric Detection
}

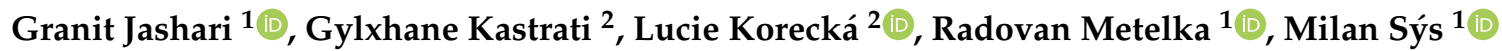 \\ and Amir M. Ashrafi ${ }^{3, *(1)}$
}

1 Department of Analytical Chemistry, Faculty of Chemical Technology, University of Pardubice, Studentská 573, 53210 Pardubice, Czech Republic; granit.jashari@student.upce.cz (G.J.); radovan.metelka@upce.cz (R.M.); milan.sys@upce.cz (M.S.)

2 Department of Biological and Biochemical Sciences, Faculty of Chemical Technology, University of Pardubice, Studentská 573, 53210 Pardubice, Czech Republic; gylxhane.kastrati@student.upce.cz (G.K.); lucie.korecka@upce.cz (L.K.)

3 Department of Chemistry and Biochemistry, Mendel University in Brno, CZ-613 00 Brno, Czech Republic

* Correspondence: amirmansoor.ashrafi@mendelu.cz; Tel.: +420-545-133-035

Citation: Jashari, G.; Kastrati, G. Korecká, L.; Metelka, R.; Sýs, M.; Ashrafi, A.M. Electrochemical Behaviour of Tocopherols: Possibilities of Their Simultaneous Voltammetric Detection. Appl. Sci. 2021, 11, 8095. https://doi.org/ 10.3390/app11178095

Academic Editor: Luca Mazzoni

Received: 19 July 2021

Accepted: 24 August 2021

Published: 31 August 2021

Publisher's Note: MDPI stays neutral with regard to jurisdictional claims in published maps and institutional affiliations.

Copyright: (c) 2021 by the authors. Licensee MDPI, Basel, Switzerland. This article is an open access article distributed under the terms and conditions of the Creative Commons Attribution (CC BY) license (https:/ / creativecommons.org/licenses/by/ $4.0 /)$.

\begin{abstract}
An electroanalytical study for possible simultaneous detection of three naturally occurring isomers of vitamin $\mathrm{E}(\alpha, \gamma$, and $\delta$-tocopherol) was performed. This research includes several optimization steps, such as selection of electrode material, composition of working medium, selection of electrochemical technique, and parameters of square-wave voltammetry (SWV), to reach a welldefined recognition of peaks. A glassy carbon electrode, $99.9 \%$ acetonitrile containing $0.1 \mathrm{~mol} \mathrm{~L}^{-1}$ lithium perchlorate, SWV at the potential step of $1 \mathrm{mV}$, potential amplitude of $25 \mathrm{mV}$, and frequency of $25 \mathrm{~Hz}$ were decided as the most suitable working conditions. Nevertheless, the corresponding anodic peaks were not sufficiently separated due to their overlapping. Thus, four standard evaluation methods (polynomial or linear baseline, zero base, and deconvolution) were compared, and the last-mentioned method was chosen as optimum. Similar linear ranges from $3.0 \times 10^{-6}$ to $1.0 \times 10^{-5} \mathrm{~mol} \mathrm{~L}^{-1}$ were obtained for $\alpha, \gamma$, and $\delta$-tocopherol, characterized by determination coefficient of $0.998,0.985$, and 0.994 , quantification limits of $11.28,2.70$, and $3.67 \times 10^{-6} \mathrm{~mol} \mathrm{~L}^{-1}$ and detection limits of $3.72,0.89$, and $1.21 \times 10^{-6} \mathrm{~mol} \mathrm{~L}^{-1}$, respectively. A recovery from 72.0 to $128.5 \%$ for different concetration ratios of tocopherols has been achieved. This recovery range is in the accordance with values reported for liquid chromatography.
\end{abstract}

Keywords: evaluation methods; glassy carbon electrode; simultaneous detection; square wave voltammetry; tocopherols

\section{Introduction}

Tocopherols as major forms of vitamin E (VE) are considered as naturally occurring lipophilic phenolic antioxidants, especially in vegetable oils such as corn, soybean, cottonseed, and sesame [1]. Often, they are found in pharmaceuticals and cosmetics products due to their biological activity [2-4], which consists of polyunsaturated fatty acids and their esters, renowned for inhibiting free-radical chain auto-oxidation [5-9]. The dosage of tocopherols for dietary intake is important because they protect the phospholipid bilayer from free radicals. It has been suggested that the biggest role of VE in the human body is the protection from different aggressive processes such as cancer, especially hepatocellular carcinoma (HCC), and prevention of the progression of pre-cancerous lesions, cataracts, and different cardiovascular diseases. Its deficiency may contribute to the most common circulatory disorders [3,10-13], such as fertility disorder, Alzheimer's disease, etc. [14].

From the chemical point of view, it is known that VE comprises two main groups, namely tocopherols and tocotrienols. They are usually assorted based on their numbers of methyl groups on the chromanol ring, which has an extended alkyl (phytyl) chain in the 
2-position responsible for their lipophilic properties [5,15,16]. Classification of $\alpha-, \beta-, \gamma-$, and $\delta$-forms of tocopherols is based on the degree of methylation.

Common samples with natural origin are a mixture of these forms. It is worth mentioning that $\beta$-tocopherol presenting negligible content [17] is not analytically important, while pharmaceutical and cosmetic products are rich in $\alpha$-tocopherol $(\alpha-\mathrm{TOH})$ and $\alpha$-tocopheryl acetate $(\alpha-$ TOAc) content. Generally, high-performance liquid chromatography (HPLC) coupled with ultraviolet or fluorescence detector is used as a standard analytical method for the analysis of tocopherols isomers $[4,18]$. The sample preparation, including saponification with the presence of an antioxidant and subsequent extraction into an organic solvent can cause significant losses of vitamin E [12,19,20].

Hence, a voltammetric approach in the analysis of tocopherols is proposed as an interesting alternative due to easier sampling, less time-consuming analysis, and low operating costs [19]. As fat-soluble antioxidants (occurring in reduced forms), they are considered as electroactive compounds [21,22], which can be anodically oxidized at various working electrodes (glassy carbon [23], platinum electrode [24], and glassy carbon paste electrode [12] in pure organic solvents or in their aqueous mixtures). Voltammetric determination of VE in pure aqueous solution is possible to be performed after their adsorptive/extractive accumulation onto the surface of the working electrode (medium-exchange procedure) [12]

Several studies have been reported on the simultaneous voltammetric determination of tocopherols. In all cases, an overlapping of their corresponding anodic peaks was observed [21-26]. In 1973, an initial electrochemical study of individual tocopherols was reported by McBride and Evans [25]. In 1992, a scientific group around Clough began to deal with their simultaneous electrochemical detection [21]. Unfortunately, no improvement in their separation using voltammetric approach has been reached. Later, Coatanea performed an analysis of tocopherols mixtures at platinum microelectrode using differential pulse voltammetry (DPV). However, a broad oxidation peak was observed due to the influence of matrix (edible oils) [26]. Later, Diaz utilized various voltammetric techniques combined with chemometric methods with the aim to resolve the overlapping voltammetric signals of individual tocopherols [23].

In comparison with the above-mentioned studies, the effects of organic solvent, water content, and the presence of surfactant on overlapping signals of tocopherols have not been studied yet. These and many other factors, such as working electrode materials, surface modifications, selection of voltammetric techniques, and parameters of voltammetric techniques are investigated in the present study. Moreover, different ways of performing the evaluation of peaks in voltammetric analysis of tocopherols are compared. The obtained results suggest that an approach utilizing a deconvolution of signals seems to be viable for the simultaneous determination of tocopherols in various food samples.

\section{Materials and Methods}

\subsection{Reagents and Chemicals}

The lithium perchlorate, $99.99 \%$ surfactants such as Triton X-100, 98\% sodium dodecyl sulfate (SDS), $99-102.0 \%$ cetylpyridinium chloride (CPC), $99 \%$ cetyltrimethylammonium bromide (CTAB), and analytical standards of $(+)-\alpha$-tocopherol, $(+)-\gamma$-tocopherol and $(+)-\delta-$ tocopherol were purchased from Merck KGaA (Darmstadt, Germany). Organic solvents, namely $99.9 \%$ acetonitrile $(\mathrm{MeCN}), 96 \%$ ethanol (EtOH), 99.8\% dimethylformamide (DMF), and $99.9 \%$ propylene carbonate $(\mathrm{CP})$, were obtained from Lach-Ner, s.r.o. (Neratovice, Czech Republic). Multi-walled carbon nanotubes (MWCNTs) of diameter 10-30 nm, length 5-15 $\mu \mathrm{m}$, and specific surface area $40-300 \mathrm{~m}^{2} \mathrm{~g}^{-1}$ were from Shenzhen Nanotech Port Co., Ltd. (Shenzhen, China). An alumina powder with particle size of $1.0 \mu \mathrm{m}$ was obtained from Metrohm Česká republika s.r.o. (Prague, Czech Republic). Ultrapure water with resistivity lower than $18.3 \mathrm{M} \Omega \mathrm{cm}$ was prepared by Milli- ${ }^{\circledR}$ system from Merck Millipore (Burlington, NJ, USA). 


\subsection{Instrumentation}

Different electrodes from Metrohm with the same diameter $(3 \mathrm{~mm})$ have been used for this study, namely glassy carbon electrode (GCE), gold disk electrode (AuE), platinum disk electrode (PtE), and boron-doped diamond electrode (BDDE). In addition, GCE was modified with a thin layer of MWCNTs (GCE/MWCNTs). Pyrolytic graphite electrodes (PGE) prepared at the Institute of Biophysics of the Czech Academy of Sciences were also tested. All voltammetric measurements were carried out through a common three-electrode system consisting of one of the tested working electrodes, saturated calomel electrode (SCE) with $99.9 \% \mathrm{MeCN}$ containing $0.1 \mathrm{~mol} \mathrm{~L}^{-1} \mathrm{LiClO}_{4}$ as a salt bridge (reference) and platinum wire (auxiliary electrode) in a conventional electrochemical glass cell. The electrode system was connected to a potentiostat/galvanostat PGSTAT101 operated with Nova 1.11 software from Metrohm. This software enables evaluation of peak-shaped electrochemical signals with several evaluation methods, such as linear and polynomial baseline and reading of peak current from zero base. Moreover, a deconvolution method was performed by OriginPRO ${ }^{\circledR}$ software version 9.0 from OriginLab Corporation (Northampton, MA, USA). The instrumentation used together with evaluation methods are shown in Figure 1.
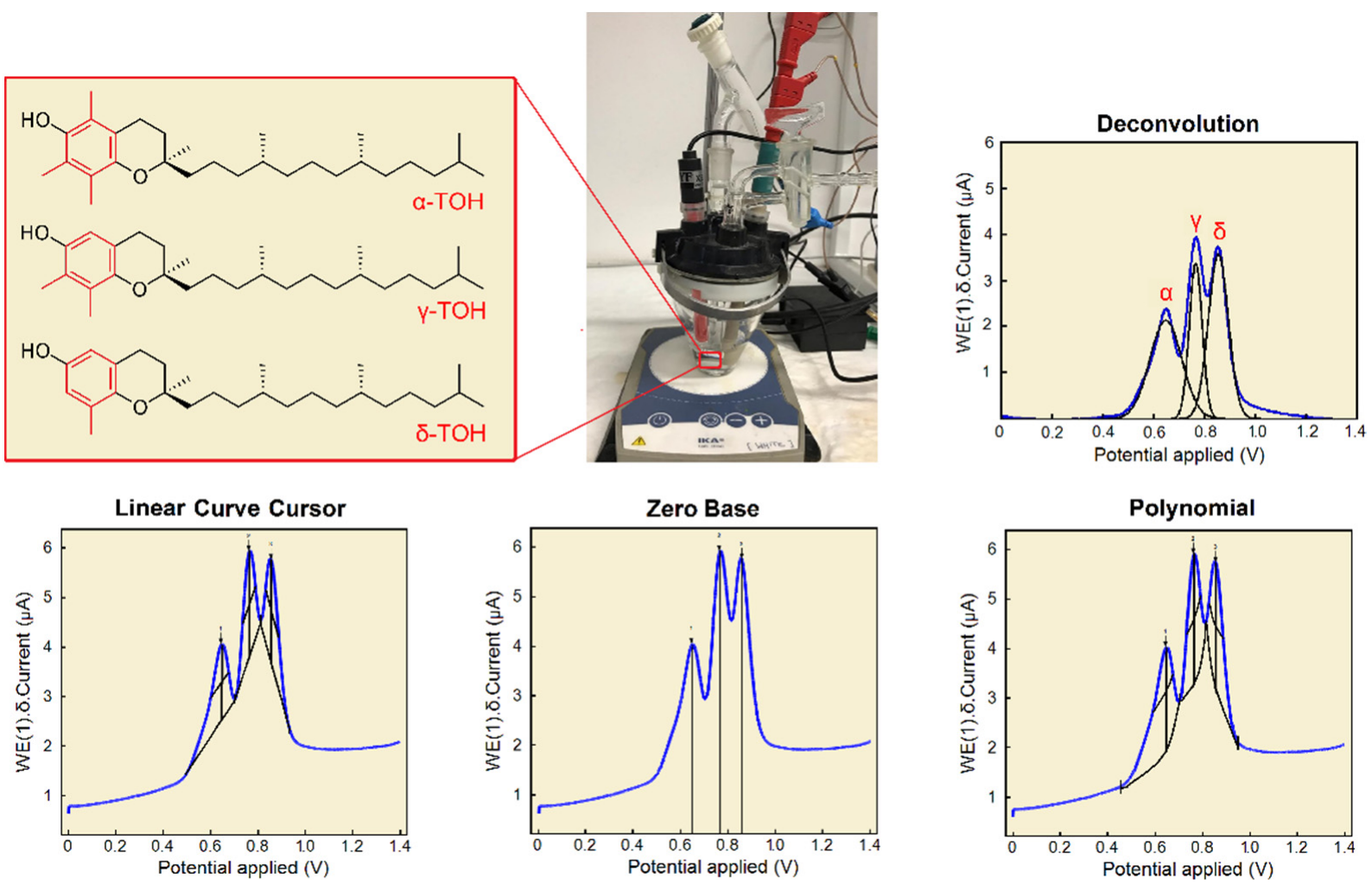

Figure 1. Instrumentation and principles of evaluation methods for simultaneous electrochemical detection of different tocopherols.

\subsection{Pretreatment and Preparation of Working Electrodes}

Surfaces of solid electrodes were renovated on a polishing pad with water suspension of $\mathrm{Al}_{2} \mathrm{O}_{3}$ powder (particle size $1.0 \mu \mathrm{m}$ ) for $30 \mathrm{~s}$. Then, the polished surfaces were washed by stream of pure ethanol and dried using a pulp paper. To prepare GCE/MWCNTs, an aliquot of $10 \mu \mathrm{L}$ MWCNTs dispersion in DMF $\left(2 \mathrm{mg} \mathrm{mL}^{-1}\right)$ was applied on pre-treated GCE surface and left to dry at laboratory conditions for one hour [27].

\subsection{Procedures}

Linear sweep voltammetry (LSV) was applied as the initial voltammetric technique for a mixture containing $50 \mu \mathrm{mol} \mathrm{L}-1$ of each tocopherol at GCE with a potential range from 0 
to $+1.0 \mathrm{~V}$, potential step ( $\left.E_{\text {step }}\right) 2.5 \mathrm{mV}$, and different scan rates $(v)$. Due to low sensitivity and high overlapping of peaks in LSV, two more useful pulse voltammetric techniques were tested. Differential pulse voltammetry (DPV) of $10 \mu \mathrm{mol} \mathrm{L}^{-1}$ tocopherols at GCE with a potential range from 0 to $+1.2 \mathrm{~V}$, different potential step $\left(E_{\text {step }}\right)$, potential amplitudes $\left(E_{\mathrm{ampl}}\right)$, and scan rates were compared with square-wave voltammetry (SWV).

The last-mentioned voltammetric technique was investigated for simultaneous electrochemical detection of $1-900 \mu \mathrm{mol} \mathrm{L}^{-1}$ tocopherols at GCE within a potential range from 0 to $+1.2 \mathrm{~V}$ using different $E_{\text {step }}, E_{\mathrm{ampl}}$, and frequencies $(f)$ with the intent to obtain optimum peaks separation. Each voltammetric measurement was repeated minimally three times. All additional changes in working parameters are shown in the legends of the corresponding figures.

\section{Results and Discussion}

\subsection{Effect of Electrode Material}

Tocopherols represent phenolic compounds differing in the number of methyl groups in the chromanol ring. An electrochemical oxidation of chromanol ring can be carried out at different electrode materials in pure $\mathrm{MeCN}$, as shown in Figure 2. GCE provided the most suitable peaks separation, namely $\alpha-\mathrm{TOH}$ at $0.645 \mathrm{~V}, \gamma-\mathrm{TOH}$ at $0.752 \mathrm{~V}$, and $\delta-\mathrm{TOH}$ at $0.857 \mathrm{~V}$, due to slower charge transfer at carbon-based over metal-based electrodes [28]. Hence, other carbon-based electrode materials were compared with GCE; however, no improvement was observed.
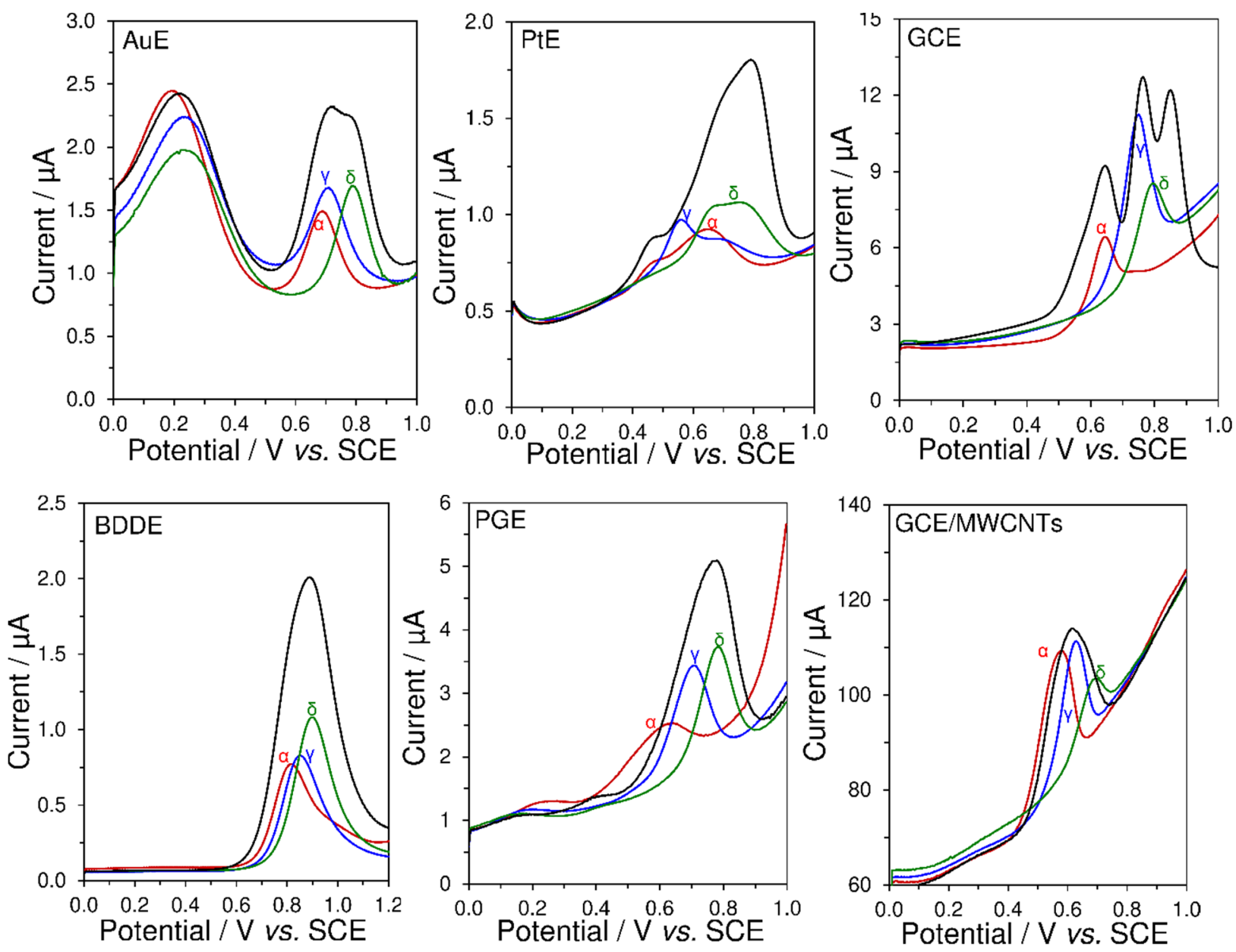

Figure 2. SWV of $50 \mu \mathrm{mol} \mathrm{L}-1 \alpha-\mathrm{TOH}, \gamma-\mathrm{TOH}$, and $\delta-\mathrm{TOH}$ at different tested working electrodes. The corresponding experiments were performed in $99.9 \% \mathrm{MeCN}$ containing $0.1 \mathrm{~mol} \mathrm{~L}^{-1} \mathrm{LiClO}_{4}$ at $E_{\text {step }}=5 \mathrm{mV}, E_{\mathrm{ampl}}=25 \mathrm{mV}$, and $f=20 \mathrm{~Hz}$. 
In 2006, Richard et al. explained the electrochemical behaviour of all tocopherol forms and proposed ECE mechanism [5]. Furthermore, they observed a dependence of their anodic peak potentials on numbers of methyl groups on the chromanol ring [5]. Fundamentally, methyl groups have a positive inductive effect, and therefore they release electron density into the benzene ring since these methyl groups, being sp3 hybridized, are less electronegative than the sp2 hybridized aromatic carbons [5]. Accordingly, investigated tocopherols are anodically oxidized in the following order: $\alpha$-TOH (three), $\beta-\mathrm{TOH}$ (two), $\gamma$ - $\mathrm{TOH}$ (two), and $\delta$-TOH (one) methyl groups [24].

\subsection{Effect of Working Medium}

Since tocopherols and tocotrienols are lipophilic compounds, they are soluble in polar organic solvents (DMF, $\mathrm{PC}, \mathrm{EtOH}$, and $\mathrm{MeCN}$ ). The above-mentioned solvents and their aqueous/organic mixtures containing $0.1 \mathrm{~mol} \mathrm{~L}^{-1} \mathrm{LiClO}_{4}$ were examined to find a compatible working medium in which the anodic peaks will be well-defined. According to the results shown in Figure 3A, two broad anodic peaks with low current responses were observed in DMF and PC. In contrast, three overlapping peaks were observed in the case of using $\mathrm{EtOH}$ and $\mathrm{MeCN}$, where the latter represents the best choice due for high resolution of individual peaks. Figure $3 \mathrm{~B}$ points to the fact that the presence of water in organic solvents caused a shift of anodic peaks to more negative potentials and significantly decreased their current responses. This phenomenon can be attributed to easier deprotonation of hydroxyl group in aqueous environment than in pure organic solvents [29].
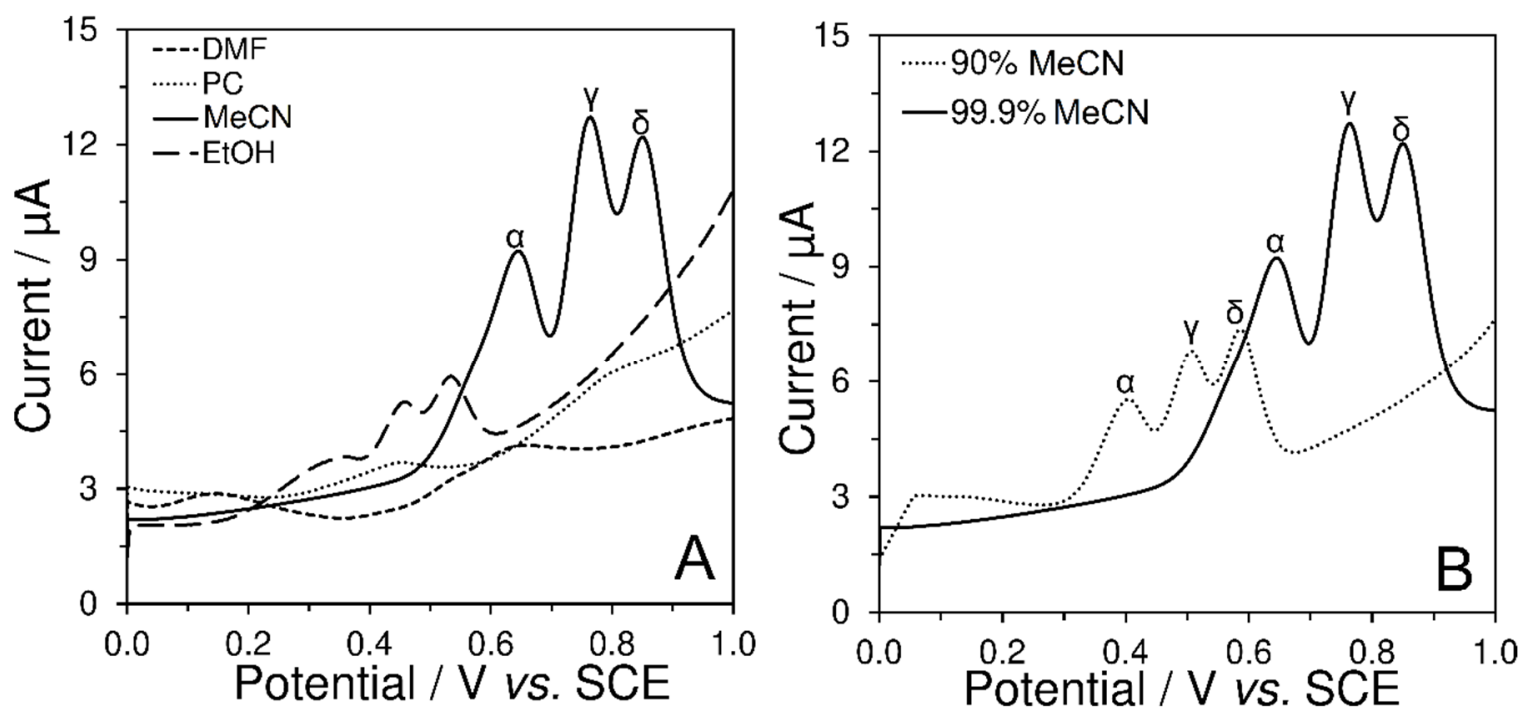

Figure 3. SWVs of $50 \mu \mathrm{mol} \mathrm{L}{ }^{-1}$ tocopherols obtained at GCE in different organic solvents (A) and different content of water (B) containing $0.1 \mathrm{~mol} \mathrm{~L}^{-1} \mathrm{LiClO}_{4}$ at $E_{\text {step }}=1 \mathrm{mV}, E_{\text {ampl }}=25 \mathrm{mV}$ and $f=20 \mathrm{~Hz}$, the potential was scanned from 0.0 to $1.0 \mathrm{~V}$.

Generally, it is known that the presence of surfactants increases the solubility of non-polar substances in polar organic solvents and facilitates the charge transfer at the working electrode due to their ability to reduce surface tension. For that reason, the effect of different contents $\left(0.1,0.01\right.$, and $\left.0.001 \mathrm{~mol} \mathrm{~L}^{-1}\right)$ of nonionic (Triton X-100), anionic (SDS), and cationic (CPC and $\mathrm{CTAB}$ ) surfactants on peaks separation was investigated. It was observed that presence of surfactant did not improve overlapping of adjacent signals and rather caused a deterioration in peak current responses (see Figure S1 in the Supplementary Materials). Finally, the effect of electrode material and composition of working medium on anodic peak potentials of tocopherols are included in Table 1. 
Table 1. Comparison of electrode material and working medium on anodic potential peaks.

\begin{tabular}{|c|c|c|c|c|c|c|}
\hline \multirow{2}{*}{ Electrode } & \multirow{2}{*}{ Method } & \multirow{2}{*}{ Working Medium } & \multicolumn{3}{|c|}{ Anodic Peak Potential (V) } & \multirow[b]{2}{*}{ Reference } \\
\hline & & & $\alpha-\mathrm{TOH}$ & $\gamma$-TOH & $\delta$-ТOH & \\
\hline GCPE & ExSV-SWV & $\mathrm{H}_{2} \mathrm{O}$ and acetone $(40: 60)$ & 0.475 & 0.520 & 0.540 & [12] \\
\hline GCE & DPV & Benzene and $\mathrm{MeOH}(1: 2)$ & 0.644 & 0.714 & 0.804 & [19] \\
\hline GCE & DPV & Hexane and EtOH (40:60) & 0.475 & 0.550 & 0.665 & [23] \\
\hline PtE & DPV & Glacial acetic acid & 0.692 & 0.755 & 0.889 & [24] \\
\hline GCE & SWV & $\mathrm{MeCN}$ & 0.645 & 0.753 & 0.857 & This work \\
\hline
\end{tabular}

Notes: GCPE; glassy carbon paste electrode and ExSV; extractive stripping voltammetry.

\subsection{Selection of Voltammetric Technique}

A comparison between LSV, DPV, and SWV in simultaneous electrochemical detection of tocopherols at scan rate of $25 \mathrm{mV} \mathrm{s}^{-1}$ is shown in Figure S2. Despite the low background current for LSV, it was almost impossible to distinguish the individual oxidation signals. The peak separation was similar in both other pulse voltammetric techniques. SWV was selected and preferred for further optimisation steps due to higher peak current responses.

\subsection{Optimisation of Square-Wave Voltammetry}

Herein, it was observed that finding the optimum working parameters for peak separation is crucial. These parameters included potential step $\left(E_{\text {step }}\right)$, frequency $(f)$, and potential amplitude $\left(E_{\text {ampl }}\right)$. For SWV, it is known that the setting of $E_{\text {step }}$ and $f$ defines the final scan rate $(v)$, which may have the main effect on the peak separation. The whole optimisation of SWV parameters is presented in Figure S3. It was found that the potential step has the main effect on peak separation when the values higher than $1 \mathrm{mV}$ caused significant peaks overlapping. The other two parameters did not have any effect on peak separation. The peak current responses only increased with higher values of these two parameters. For $E_{\text {ampl }}$ values higher than $25 \mathrm{mV}$, frequency $25 \mathrm{~Hz}$, and potential step $1 \mathrm{mV}$, there was no effect found on peak separation. Therefore, these values were chosen as optimum for the construction of calibration curves for different concentration ratios.

\subsection{Effect Concentration Ratios and Evaluation Methods on Analytical Performance}

In general, peak height and width increase with a higher concentration of analyte. It follows that concentration ratio can significantly distort the recognition of individual tocopherols. Hence, it was necessary to find out if investigated tocopherol compounds overlap within the scope of calibration measurement, which could affect the main analytical characteristics, namely linear range, limit of detection (LOD), limit of quantification (LOQ), precision, and accuracy.

Figure $4 \mathrm{~A}-\mathrm{C}$ represents calibration voltammograms $\left(20-200 \mu \mathrm{mol} \mathrm{L}^{-1}\right)$ of a selected form of tocopherols, whereas two others had a constant concentration of $50 \mu \mathrm{mol} \mathrm{L}{ }^{-1}$. Additionally, calibration measurements were performed to find out mutual influencing, where the concentration of two forms was simultaneously increased, as shown in Figure 4D-F. Resultant voltammograms showed that overlapping of $\gamma-\mathrm{TOH}$ and $\delta$ - $\mathrm{TOH}$ anodic peaks is more evident if one of these forms has a higher concentration than the other, whereas the mutual recognition of $\alpha-\mathrm{TOH}$ and $\delta-\mathrm{TOH}$ peaks increased with a higher concentration of both forms. Surprisingly, the overlapping was suppressed if concentrations of all three forms (3-300 $\mu \mathrm{mol} \mathrm{L}^{-1}$ ) were mutually increased (see Figure $4 \mathrm{G}$ ). 

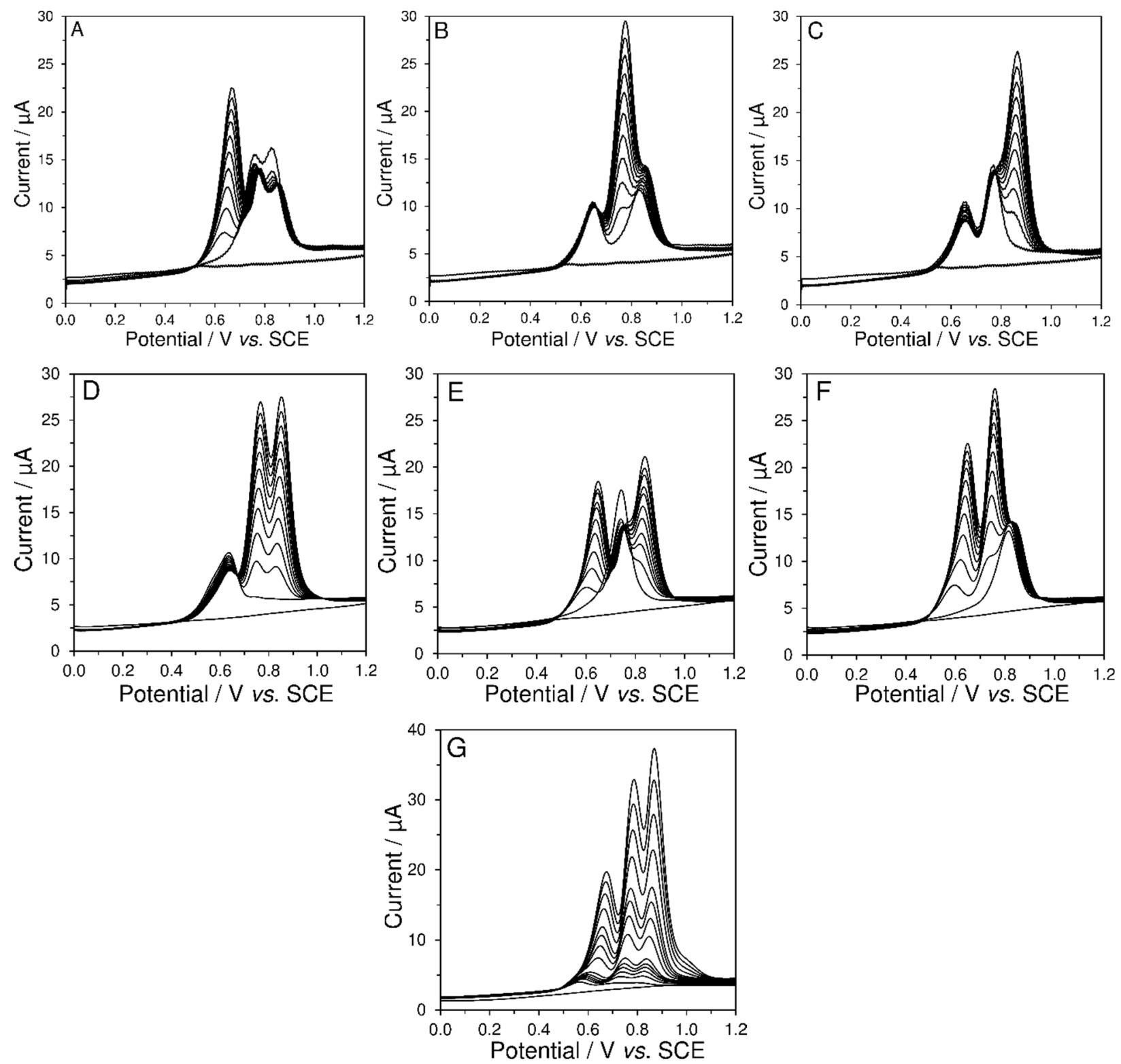

Figure 4. SWVs of 20-200 $\mu \mathrm{mol} \mathrm{L}{ }^{-1}$ of one tocopherol form when two others had a constant concentration of $50 \mu \mathrm{mol} \mathrm{L}-1$

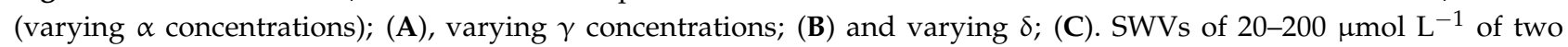
tocopherols when one had a constant concentration of $50 \mu \mathrm{mol} \mathrm{L}{ }^{-1}$ (varying $\gamma$ and $\delta$ concentrations); (D) varying $\alpha$ and $\delta$ concentrations; (E) and varying $\alpha$ and $\gamma$ concentrations;(F). Simultaneous voltametric detection of $3-300 \mu \mathrm{mol} \mathrm{L}-1$ of all tocopherol forms $(\mathbf{G})$. All voltammograms were obtained at GCE in pure MeCN containing $0.1 \mathrm{~mol} \mathrm{~L}^{-1} \mathrm{LiClO}_{4}, E_{\text {step }}=1 \mathrm{mV}$, $E_{\mathrm{ampl}}=25 \mathrm{mV}$, and $f=25 \mathrm{~Hz}$. The potential was scanned from 0.0 to $1.2 \mathrm{~V}$.

Overview of all analytical parameters obtained during simultaneous voltammetric detection of investigated tocopherols is presented in Table 2. To achieve the coefficient of determination $\left(R^{2}\right)$ in the accepted value higher than 0.9900 , calibration ranges from 3 to $100 \mu \mathrm{mol} \mathrm{L}^{-1}$ for all tocopherol forms can be taken into account. High positive yintercept $(q)$ values and low sensitivity $(k)$ of appropriate equations of the calibration curves $\left(q>0.2 \mu \mathrm{A}\right.$ and $\left.k<0.09 \mu \mathrm{A} \mathrm{mol}^{-1} \mathrm{~L}\right)$ were obtained when polynomial, linear curve cursor, and zero base evaluation methods were used. On the other hand, if the deconvolution evaluation method is preferred, values of $q<0.1 \mu \mathrm{A}$ and $k>1.0 \mu \mathrm{A} \mathrm{mol}^{-1} \mathrm{~L}$ will be obtained. Therefore, the deconvolution should be preferred. From all LOQ values shown in Table 2, it seems that the present study could help to develop a simple voltammetric 
method for simultaneous determination of tocopherols in margarines [12], edible vegetable oils [17], nuts, and seeds [30].

Table 2. All analytical parameters with four different methods for evaluation of signals.

\begin{tabular}{|c|c|c|c|c|c|c|c|c|c|c|c|c|}
\hline & \multicolumn{3}{|c|}{$\begin{array}{l}\text { Polynomial } \\
(\mu \mathrm{mol} \mathrm{L}-1)\end{array}$} & \multicolumn{3}{|c|}{$\begin{array}{c}\text { Linear Curve Cursor } \\
\left(\mu \mathrm{mol} \mathrm{L}^{-1}\right)\end{array}$} & \multicolumn{3}{|c|}{$\begin{array}{c}\text { Zero Base } \\
(\mu \mathrm{mol} \mathrm{L}-1)\end{array}$} & \multicolumn{3}{|c|}{$\begin{array}{l}\text { Deconvolution } \\
(\mu \mathrm{mol} \mathrm{L}-1)\end{array}$} \\
\hline & $\alpha-\mathrm{TOH}$ & $\gamma-\mathrm{TOH}$ & $\delta-\mathrm{TOH}$ & $\alpha-\mathrm{TOH}$ & $\gamma-\mathrm{TOH}$ & $\delta-\mathrm{TOH}$ & $\alpha-\mathrm{TOH}$ & $\gamma-\mathrm{TOH}$ & $\delta-\mathrm{TOH}$ & $\alpha$-ТОН & $\gamma$-TOH & $\delta-\mathrm{TOH}$ \\
\hline LOD & 2.30 & 0.42 & 0.60 & 2.09 & 0.28 & 0.49 & 3.39 & 1.21 & 1.53 & 3.72 & 0.89 & 1.21 \\
\hline LOQ & 6.99 & 1.30 & 1.83 & 6.34 & 0.85 & 1.50 & 10.27 & 3.68 & 4.65 & 11.28 & 2.70 & 3.67 \\
\hline $\begin{array}{l}\text { Linear } \\
\text { range }\end{array}$ & 3-100 & 3-100 & 3-100 & 3-100 & 3-100 & 3-100 & 3-100 & 3-100 & $3-200$ & $3-100$ & $3-100$ & $3-100$ \\
\hline $\mathrm{R}^{2}$ & 0.996 & 0.994 & 0.993 & 0.997 & 0.991 & 0.996 & 0.995 & 0.982 & 0.990 & 0.998 & 0.985 & 0.994 \\
\hline
\end{tabular}

From the analytical point of view, determination of precision and accuracy is necessary to obtain relevant results. The precision, defined as the result of variability found with repeated measurements, was calculated for tocopherols mixture $\left(50 \mu \mathrm{mol} \mathrm{L} \mathrm{L}^{-1}\right.$ of each form) measured ten times and presented as relative standard deviation (RSD). Values of $5.48 \%, 4.88 \%$, and $7.87 \%$ RSD for polynomial baseline; $4.78 \%, 0.11 \%$, and $0.20 \%$ RSD linear baseline; $2.01 \%, 0.15 \%$, and $0.05 \%$ RSD for zero base; and $1.66 \%, 2.75 \%$, and $1.94 \%$ RSD for deconvolution were calculated. For a significance level of $5 \%$, it is evident that only the polynomial evaluation method is not satisfactory for analytical purposes.

Table 3 shows the comparison of evaluation methods used in determination of accuracy for different model samples having the randomly chosen contents of investigated tocopherols. In this case, the accuracy is presented as recovery values (\%). Acceptable accuracy values ranging from $72 \%$ to $119 \%$ can be accepted only for the deconvolution method, which is comparable with recovery ranges from $71 \%$ to $116 \%$ and from $77 \%$ to $85 \%$ recommended for tocopherols determination in nuts and virgin olive oils using QuEChERS-liquid chromatography and reversed-phase HPLC with spectrophotometric detection, respectively [30].

Table 3. Comparison evaluation methods in determination of accuracy presented as recovery values.

\begin{tabular}{|c|c|c|c|c|c|c|c|c|c|c|c|c|}
\hline \multirow{2}{*}{$\begin{array}{c}\text { Concetration Ratios } \\
(\mu \mathrm{mol} \mathrm{L}-1)\end{array}$} & \multicolumn{3}{|c|}{ Polynomial (\%) } & \multicolumn{3}{|c|}{ Linear Curve Cursor (\%) } & \multicolumn{3}{|c|}{ Zero Base (\%) } & \multicolumn{3}{|c|}{ Deconvolution (\%) } \\
\hline & $\alpha-\mathrm{TOH}$ & $\gamma$-TOH & $\delta$-TOH & $\alpha-\mathrm{TOH}$ & $\gamma$-TOH & $\delta-\mathrm{TOH}$ & $\alpha-\mathrm{TOH}$ & $\gamma-$ TOH & $\delta-\mathrm{TOH}$ & $\alpha-\mathrm{TOH}$ & $\gamma$-TOH & $\delta-\mathrm{TOH}$ \\
\hline $30: 60: 45$ & 58.33 & 48.19 & 46.24 & 45.78 & 49.07 & 48.08 & 54.54 & 76.18 & 101.60 & 105.80 & 102.2 & 105.50 \\
\hline $45: 75: 60$ & 44.10 & 58.90 & 35.56 & 47.49 & 55.75 & 43.20 & 53.36 & 74.49 & 91.35 & 85.95 & 97.75 & 99.07 \\
\hline $60: 90: 75$ & 47.70 & 54.70 & 33.97 & 49.12 & 58.31 & 40.63 & 54.90 & 72.81 & 86.07 & 80.00 & 97.84 & 99.65 \\
\hline $45: 60: 30$ & 26.38 & 65.28 & 52.15 & 30.94 & 70.77 & 55.52 & 19.52 & 62.80 & 82.41 & 81.34 & 95.18 & 118.50 \\
\hline $60: 75: 45$ & 34.77 & 69.99 & 51.65 & 33.10 & 70.19 & 54.83 & 31.35 & 65.21 & 85.32 & 90.81 & 102.70 & 111.50 \\
\hline $75: 90: 60$ & 39.80 & 66.11 & 70.97 & 32.86 & 69.92 & 61.25 & 40.30 & 65.30 & 86.73 & 79.52 & 93.64 & 106.90 \\
\hline $60: 30: 45$ & 41.91 & 55.82 & 83.20 & 43.29 & 28.60 & 88.21 & 24.57 & 68.49 & 67.75 & 73.49 & 111.70 & 101.40 \\
\hline $75: 45: 60$ & 37.89 & 45.90 & 68.47 & 41.36 & 36.46 & 75.64 & 32.34 & 69.62 & 71.37 & 73.86 & 109.70 & 71.37 \\
\hline $90: 60: 75$ & 38.84 & 44.02 & 61.62 & 40.54 & 39.66 & 65.31 & 36.01 & 67.25 & 69.68 & 72.03 & 100.50 & 95.57 \\
\hline
\end{tabular}

Obtained results showed that it is not yet possible to perfectly split the anodic peaks of $\alpha-\mathrm{TOH}, \gamma-\mathrm{TOH}$, and $\delta$-TOH differing only in the number of methyl groups in chromanol ring. Nevertheless, it was found that the type of working electrode material, composition of detection medium, set parameters of electrochemical technique, and selection of evaluation method have a significant effect in their sufficient resolution so that the individual signals can be quantified. The distance around $100 \mathrm{mV}$ of individual oxidation peaks $(0.645 \mathrm{~V}$ for $\alpha-\mathrm{TOH}, 0.753 \mathrm{~V}$ for $\gamma-\mathrm{TOH}$ and 0.857 for $\delta-\mathrm{TOH}$ ) has been achieved at optimum working conditions.

\section{Conclusions}

In this contribution, an electrochemical behaviour of naturally occurring tocopherols $(\alpha-\mathrm{TOH}, \gamma-\mathrm{TOH}$, and $\delta-\mathrm{TOH})$ was investigated to find out optimum working conditions for their simultaneous voltammetric detection. In comparison with the previously reported scientific papers $[12,19,23,24]$, simultaneous voltammetric detection of investigated 
tocopherols was simplified and significantly higher peaks separation was reached using SWV in pure MeCN at GCE and necessary low potential step of $1 \mathrm{mV}$. However, it seems that analysis of voltammetric signals is not possible without the use of mathematic decomposition (deconvolution) of overlapping peaks because standard evaluation methods included in Nova 1.11 software (polynomial and linear baseline and zero base reading) are not sufficient. Due to high precision and comparable accuracy with standard HPLC methods, it can be assumed that the present electrochemical study includes appropriate knowledge and instructions useful for the development of a direct voltammetric method for simultaneous determination of $\alpha-\mathrm{TOH}, \gamma-\mathrm{TOH}$, and $\delta-\mathrm{TOH}$ in different foodstuffs.

Supplementary Materials: The following are available online at https:/ / www.mdpi.com/article / 10.3390/app11178095/s1, Figure S1: Voltammograms of $50 \mu \mathrm{mol} \mathrm{L}^{-1} \alpha-\mathrm{TOH}, \gamma$-TOH, and $\delta$-TOH at GCE in pure $\mathrm{MeCN}$ containing $0.1 \mathrm{~mol} \mathrm{~L}^{-1} \mathrm{LiClO}_{4}$ and $0.001 \mathrm{~mol} \mathrm{~L}^{-1} \mathrm{CPC}$, SDS, or Triton $\mathrm{X}-100$ at $E_{\text {step }}=1 \mathrm{mV}, E_{\mathrm{ampl}}=25 \mathrm{mV}$, and $f=20 \mathrm{~Hz}$. Figure S2: Comparison of voltammetric techniques in simultaneous determination of $50 \mu \mathrm{mol} \mathrm{L}^{-1} \alpha-\mathrm{TOH}, \gamma-\mathrm{TOH}$, and $\delta$-TOH for LSV and $10 \mu \mathrm{mol} \mathrm{L}{ }^{-1}$ these tocopherols for DPV and SWV. All measurements were carried out at GCE in pure MeCN containing $0.1 \mathrm{~mol} \mathrm{~L}^{-1} \mathrm{LiClO}_{4}$. Conditions of LSV: $E_{\text {step }}=2.5 \mathrm{mV}$ and $v=25 \mathrm{mV} \mathrm{s}^{-1}$; DPV: $E_{\text {step }}=2.5 \mathrm{mV}, E_{\mathrm{ampl}}=50 \mathrm{mV}$, and $v=25 \mathrm{mV} \mathrm{s}^{-1}$; and SWV: $E_{\text {step }}=1 \mathrm{mV}, E_{\mathrm{ampl}}=25 \mathrm{mV}$, and $f=25 \mathrm{~Hz}$. Figure S3: Voltammograms of $50 \mu \mathrm{mol} \mathrm{L}{ }^{-1} \alpha-\mathrm{TOH}, \gamma-\mathrm{TOH}$, and $\delta-\mathrm{TOH}$ at GCE in pure $\mathrm{MeCN}$ containing $0.1 \mathrm{~mol} \mathrm{~L}^{-1} \mathrm{LiClO}_{4}$ at (A) $E_{\text {ampl }}=5-80 \mathrm{mV}$, $E_{\text {step }}=2.5 \mathrm{mV}$, and $f=20 \mathrm{~Hz}$; (B) $f=5-50 \mathrm{~Hz}, E_{\text {step }}=2.5 \mathrm{mV}$, and $E_{\text {ampl }}=25 \mathrm{mV}$; and (C) $E_{\text {step }}=1-15 \mathrm{mV}, E_{\text {ampl }}=25 \mathrm{mV}$, and $f=20 \mathrm{~Hz}$.

Author Contributions: Formal analysis, G.J., G.K.; methodology, L.K., R.M., M.S.; validation and author of manuscript, G.J.; final correction, R.M.; supervision, A.M.A. All authors have read and agreed to the published version of the manuscript.

Funding: This research received no external funding.

Institutional Review Board Statement: Not applicable.

Informed Consent Statement: Not applicable.

Data Availability Statement: All the relevant data are provided as the supplametary material.

Acknowledgments: Financial support from the Faculty of Chemical Technology, the University of Pardubice (project No. SGS-2021-001) is gratefully acknowledged.

Conflicts of Interest: The authors declare no conflict of interest.

\section{References}

1. Gupta, D.S.; Suh, N. Tocopherols in cancer: An update. Mol. Nutr. Food Res. 2016, 60, 1354-1363. [CrossRef]

2. Ruperez, F.J.; Martın, E.; Herrera, D.; Barbas, C. Chromatographic analysis of $\alpha$-tocopherol and related compounds in various matrices. J. Chromatogr. A 2001, 935, 45-69. [CrossRef]

3. Li, S.-G.; Xue, W.-T.; Zhang, H. Voltammetric behavior and determination of tocopherol in vegetable oils at a polypyrrole modified electrode. Electroanalysis 2006, 18, 2337-2342. [CrossRef]

4. Ana, H.M.P.S.; Guinazi, M.; Oliveria, D.S.; Lucia, C.M.D.; Reis, B.L.; Brandao, S.C.C. Method for simultaneous analysis of eight vitamin $\mathrm{E}$ isomers in various foods by high performance liquid chromatography and fluorescence detection. J. Chromatogr. A 2011, 1218, 8496-8502.

5. Gregory, W.J.; Ching, L.Y.; Richard, W.D. Significant differences in the electrochemical behavior of the $\alpha_{-}^{-}, \beta-, \gamma_{-}^{-}$, and $\delta$-tocopherols (Vitamin E). J. Chem. Phys. 2006, 110, 11540-11548.

6. Mikheeva, E.V.; Anisimova, L.S. Voltammetric determination of vitamin E ( $\alpha$-tocopherol acetate) in multicomponent vitaminized mixtures. J. Anal. Chem. 2007, 62, 413-417. [CrossRef]

7. Sies, H. Oxidative stress: Oxidants and antioxidants. Exp. Physiol. 1997, 82, 291-295. [CrossRef]

8. Niki, E.; Noguchi, N.; Tsuchihashi, H.; Gotoh, N. Interaction among vitamin C, vitamin E, and beta-carotene. Am. J. Clin. Nutr. 1995, 62, 1322S-1326S. [CrossRef] [PubMed]

9. Tesoriere, L.; Ciaccio, M.; Bongiorno, A.; Riccio, A.; Pintaudi, A.M.; Livrea, M.A. Antioxidant activity of all-trans-retinol in homogeneous solution and in phosphatidylcholine liposomes. Arch. Biochem. Biophys. 1993, 307, 217-223. [CrossRef]

10. Yuan, J.M.; Gao, Y.T.; Ong, C.N.; Ross, R.K.; Yu, M.C. Prediagnostic level of serum retinol in relation to reduced risk of hepatocellular carcinoma. J. Natl. Cancer Inst. 2006, 98, 482-490. [CrossRef] 
11. Azzi, A.; Gysin, R.; Kempna, P.; Ricciarelli, R.; Villacorta, L.; Visarius, T.; Zingg, J.M. The role of $\alpha$-tocopherol in preventing disease: From epidemiology to molecular events. Mol. Aspects Med. 2003, 24, 325-336. [CrossRef]

12. Sýs, M.; Švecová, B.; Švancara, I.; Metelka, R. Determination of vitamin E in margarines and edible oils using square wave anodic stripping voltammetry with a glassy carbon paste electrode. Food. Chem. 2017, 229, 621-627. [CrossRef]

13. Bakre, S.M.; Gadmale, D.K.; Toche, R.B.; Gaikwad, V.B. Rapid determination of alpha tocopherol in olive oil adulterated with sunflower oil by reversed phase high-performance liquid chromatography. J. Food Sci. Technol. 2015, 52, 3093-3098. [CrossRef]

14. Kastrati, G.; Jashari, G.; Sýs, M.; Švecová, B.; Arbneshi, T.; Metelka, R.; Bílková, Z.; Korecká, L. Simultaneous determination of vitamin e and vitamin $\mathrm{k}$ in food supplements using adsorptive stripping square-wave voltammetry at glassy carbon electrode. Appl. Sci. 2020, 10, 4759. [CrossRef]

15. Williams, L.L.; Webster, R.D. Electrochemically controlled chemically reversible transformation of $\alpha$-tocopherol (Vitamin E) into its phenoxonium cation. J. Am. Chem. Soc. 2004, 126, 12441-12450. [CrossRef] [PubMed]

16. Lee, S.B.; Lin, C.Y.; Gill, P.M.W.; Webster, R.D. Transformation of $\alpha$-tocopherol (Vitamin E) and related chromanol model compounds into their phenoxonium ions by chemical oxidation with the nitrosonium cation. J. Org. Chem. 2005, 70, 10466-10473. [CrossRef] [PubMed]

17. Swiglo, A.G.; Sikorska, E. Simple reversed-phase liquid chromatography method for determination of tocopherols in edible plant oils. J. Chromatogr. A 2004, 1048, 195-198. [CrossRef]

18. Khan, A.; Khan, M.I.; Iqbal, Z.; Shah, Y.; Ahmad, L.; Watson, D.G. An optimized and validated RP-HPLC/UV detection method for simultaneous determination of all-trans-retinol (Vitamin A) and $\alpha$-tocopherol (Vitamin E) in human serum: Comparison of different particulate reversed-phase HPLC columns. J. Chromatogr. B 2010, 25, 2339-2347. [CrossRef] [PubMed]

19. Lubeckyj, R.A.; Winkler-Moser, J.K.; Fhaner, M.J. Application of differential pulse voltammetry to determine the efficiency of stripping tocopherols from commercial fish oil. J. Am. Oil Chem. Soc. 2017, 94, 527-536. [CrossRef]

20. Cerretani, L.; Garcia, M.J.L.; Martinez, J.M.H.; Toschi, T.G.; Alfonso, E.F.S. Determination of tocopherols and tocotrienols in vegetable oils by nanoliquid chromatography with ultraviolet-visible detection using a silica monolithic column. J. Agric. Food Chem. 2010, 58, 757-761. [CrossRef] [PubMed]

21. Clough, A.E. The Determination of tocopherols in vegetable oils by square-wave voltammetry. J. Am. Oil Chem. Soc. 1992, 69, 456-460. [CrossRef]

22. Jaiswal, P.V.; Iljeri, V.S.; Srivastava, A.K. Voltammetric behavior of $\alpha$-tocopherol and its determination using surfactant + ethanol + water and surfactant + acetonitrile + water mixed solvent systems. Anal. Chim. Acta 2001, 441, 201-206. [CrossRef]

23. Diaz, T.G.; Meras, I.D.; Cabanillas, A.G.; Franco, M.F.A. Voltammetric behavior and determination of tocopherols with partial least squares calibration: Analysis in vegetable oil samples. Anal. Chim. Acta 2004, 511, 231-238. [CrossRef]

24. Michalkiewicz, S.; Tutaj, M.; Kaczor, M.; Malyszko, J. Electrochemical behavior of tocopherols on microelectrodes in acetic acid medium. Electroanalysis 2002, 14, 297-302. [CrossRef]

25. McBride, H.D.; Evans, D.H. Rapid Voltammetric Method for the Estimation of Tocopherols and Antioxidants in Oils and Fats. Anal. Chem. 1973, 45, 446-449. [CrossRef]

26. Coatanea, M.; Darchen, A.; Hauchard, D. Electroanalysis at ultramicroelectrodes of oils and fats: Application to the determination of Vitamin E. Sens. Actuators B Chem. 2001, 76, 539-544. [CrossRef]

27. Jain, R.; Sharma, S. Glassy carbon electrode modified with multi-walled carbon nanotubes sensor for the quantification of antihistamine drug pheniramine in solubilized systems. J. Pharm. Anal. 2012, 2, 56-61. [CrossRef]

28. Wang, G.; Zhang, L.; Zhang, J. A review of electrode materials for electrochemical supercapacitors. Chem. Soc. Rev. 2012, 41, 797-828. [CrossRef]

29. Barbosa, J.; Nebot, V.S. pH measurements in acetonitrile-water mixtures by use of a glass electrode. J. Pharm. Biomed. Anal. 1992, 10, 1047-1051. [CrossRef]

30. Zamarreno, M.M.D.; Prieto, C.F.; Rangel, M.B.; Martin, L.P. Determination of tocopherols and sitosterols in seeds and nuts by QuEChERS-liquid chromatography. Food Chem. 2016, 192, 825-830. [CrossRef] [PubMed] 